American Journal of Economics and Business Administration 3 (4): 589-595, 2011

ISSN 1945-5488

(C) 2011 Science Publications

\title{
Efficiency in the California Real Estate Labor Market
}

\author{
Dirk Yandell \\ School of Business Administration, \\ University of San Diego, San Diego, 92110, California
}

\begin{abstract}
Problem statement: This research explores the extent of market efficiency in the real estate labor market. Given a common commission rate, areas with high average home prices will generate higher agent income per home sold. If markets are efficient with few barriers to entry, additional agents per capita would be expected in high-priced areas, but each home sale would represent a larger portion of an agent's annual income so a risk premium should be present. Approach: Agent earnings and the number of homes sold were examined in selected California counties. The data provides details on over 200,000 transactions, for nearly 47,000 different real estate agents and brokers, with usable data for 477 distinct zip codes. Results: Results show that regions with a higher median home price have a greater number of parttime real estate agents and an increased number of agents per capita. Conclusion: There are fewer average commission events per agent in areas with higher housing prices, but a higher level of total commission earnings per agent to compensate for the added income risk per completed transaction.
\end{abstract}

Key words: Labor market, real estate agents, housing market, market equilibrium, risk premium, annual earnings, market efficiency

\section{INTRODUCTION}

Markets are said to perform efficiently when sufficient information and competition exist. With free entry and full knowledge, competitive forces lead to market equilibrium with zero economic profit.

The zero-profit competitive equilibrium in the traditional economic theory of the firm is defined as a market where there are large numbers of rational, competitive profit-maximizing participants who can easily enter or exit markets in search of economic profit. In an efficient market, relevant information is freely available to all participants. Active competition among the many informed and rational participants leads to prices that just cover all costs, so there is no way to earn excess profits (above a "normal" market return) in the long run.

Applied to the real estate industry, efficient markets would imply that well-informed real estate agents (and potential agents), with full knowledge of market conditions, housing prices and the level of competition in the market, would freely enter or exit the industry to maintain a competitive level of annual earnings for agents. No above-or below-normal earnings could persist because of the intense competition, free entry and full information.

The vast majority of real estate salespeople is independent contractors and can a monopolistically competitive market, where there are many sellers with small market shares, slightly differentiated products and many buyers with low barriers to entry for both buyers and sellers.

One would expect, however, that the conditions in the market for real estate agents differ slightly from those of a perfectly efficient market. In particular, entry is not always costless and information flow may be slower in real estate labor markets than in other settings, such as financial markets. In reality, the existence of transaction costs, information asymmetry and barriers to entry make most markets less than perfectly efficient.

Debate about efficient markets has resulted in numerous empirical studies examining whether specific markets are in fact "efficient" and if so to what degree. It has been shown that real estate markets are not always efficient. For example, Levitt and Syverson (2008); Miceli (1992) and Turnbull (1996) show that the existence of asymmetric information between home sellers and real estate agents leads to lower prices and more rapid sales when agents represent home sellers compared to when the agents sell their own homes. Clayton (1998); Crockett (1982) and Goolsby and Childs (1988) finds strong evidence against efficient markets in the condominium market in Vancouver.

In the market for real estate agents, state licensing and education requirements can limit supply. Licensing 
is defended as a means of maintaining quality and protecting consumers, but entry restrictions may increase agent earnings and reduce economic efficiency. Jud and Winkler (2000) develop a supply estimate for agents and find that the pass rate for licensing examinations and continuing education requirements do affect the numbers and incomes of real estate agents. On the other hand, Johnson and Loucks (1986), in a structural equation model of agent supply and demand, did not find that licensing requirements that restricted the number of agents led to higher earnings.

This study explores market efficiency by examining the real estate labor market in selected California counties. These counties show a wide range of median home values. Given the traditional compensation structure, in which the commissions earned on a home sale are some standard percentage of the selling price, agents in a high-priced home market earn more per home sold than an agent in a low-price region.

To the extent that information is available and entry is not blocked, potential profits in the high-price regions should attract new real estate agents. Although entry may be constrained and is not instantaneous, Jud and Winkler (2000) find that the supply of agents is elastic with respect to agent earnings. This suggests, all else equal, that the annual return to agents in high-price and low price regions should be similar. The implication for high-price regions is that there should be a greater number of agents per capita but fewer home sales per agent. There may also be greater discounting from the traditional commission, or increased non-price competition between agents.

Hsieh and Moretti (2003) have found that the productivity of an average real estate agent falls (fewer houses sold per hour worked) as the average price of land in a city increases. This effect can also be tested using housing prices in low-Vs high-priced regions.

Since the earnings of an agent in a high-priced home market require fewer sales than in a low-priced market, there should also be a difference in the percentage of part-time Vs full-time agents in the two markets, assuming an equal level of selling effort is required in the two regions. One would expect a greater proportion of part-time agents in areas with a higher median home price.

Introducing risk into the model allows other factors to be considered. For example, an extensive literature has examined risk premiums in financial and labor markets and the risk Vs return tradeoff. This tradeoff can be examined in the real estate labor market. Since fewer sales per agent per year would be expected, on average, in high-price markets, each home sale in a high-price region comprises a larger percentage of an agent's annual income than in a low-priced region. One implication is that high-price regions should have higher average earnings to compensate agents in those regions for the increased income risk per home sold.

Data and model: Data from selected California counties are used here to explore market efficiency, to examine the risk premium and to test for differences in full- and part-time participation between high- and lowpriced housing markets. Concentrating on California reduces any potential variation due to differences in how real estate transactions are handled across states and the different tasks real estate agents perform in different markets.

The traditional compensation structure in California residential real estate sales is that commissions earned on a home sale are a standard percentage of the selling price. The typical standard for the year used in this analysis was $6 \%$ of the sales price, split evenly between the agents representing the buyer and the seller. This is consistent with the Hsieh and Moretti (2003) findings that the average commission rate from 1980-1990 was independent of the price of housing, with a national median of $6.1 \%$. Although home sellers have always been able to bargain for a better actual rate, registered real estate agents was the only group able to add homes for sale to the Multiple Listing Service (MLS). Limited access to the MLS helped maintain the commission standard. In recent years internet-based information resources have eroded some of this market power and increased the number of discount brokers and partialservice alternatives for home sellers.

Given the common 6\% standard and assuming selling costs are similar in the two markets, agents in a high-priced home market earn more per home sold than an agent in a low price region. Assuming market information is available to participants and entry is unconstrained, potential earnings in the high-price regions should attract new real estate agents.

All else equal, market efficiency arguments suggest that the annual return to agents in high-priceand low price regions should be similar. The implication for highprice regions is that there should be a greater number of agents per capita but fewer home sales per agent.

To test these hypotheses, data on the number of sales and the dollar value of sales and commissions is needed at the individual real estate agent level. Data from California is used in this study. The number of sales and commissions earned by individual agents was obtained from a commercial service that compiles residential sales information for all recorded home sales in several California counties. Reports based on this database are typically sold to mortgage brokers, title companies and other professionals in the real estate industry. 


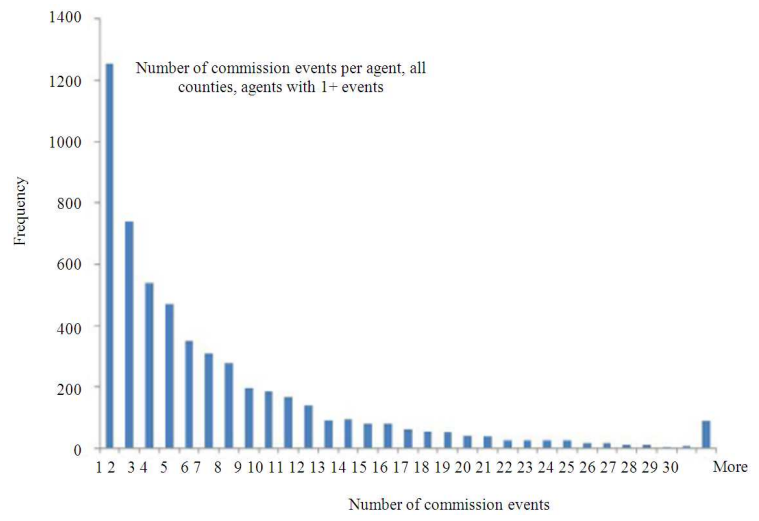

Fig. 1: Histogram of number of commission events per agent (for those with 1+ events)

Table 1: Summary statistics for commission events for those with 1+ event in 2004

\begin{tabular}{lr}
\hline Mean & 7.338 \\
\hline Median & 4.000 \\
Max & 477.000 \\
Standard deviation & 9.946 \\
\hline
\end{tabular}

Residential real estate transactions data for year 2004 was obtained for four counties in Southern California (San Diego, Orange, Riverside and San Bernardino) and five counties in Northern California (Sacramento, Stanislaus, Santa Clara, Alameda and San Joaquin). This prebubble year was used to limit the noise in housing market data generated by the recent effects of the recession and the U.S. financial crisis. Overall, the data provides details on over 200,000 transactions, for nearly 47,000 different real estate agents and brokers in these 9 counties, with usable data for 477 distinct zip codes. U.S. Census data was used for median housing prices by zip code for these counties and data from the California Association of Realtors provided demographic details on registered real estate agents in each of these counties.

Empirical evidence: Data obtained from the California Department of Real Estate (CA-DRE) showed 107,485 real estate agents and brokers with active licenses in 2004 in these nine counties. Not all who are licensed are active in the real estate market and some are only engaged part-time. The CA-DRE listing does not distinguish by active status or part-time Vs full-time employment. However, separate data was obtained from a commercial firm that compiles records of all real estate public transactions during the year. These records show 46,846 different agents who received a commission from a publicly recorded transaction in 2004. Occasionally an agent will represent both the buyer and the seller in a home sale, but most transactions involve separate agents and two commission shares.

I will define a "commission event" as an instance in which a real estate professional earns a commission when representing the buyer, the seller, or both in a publicly recorded real estate transaction. The commercial database of professionals who completed at least one transaction shows the number of transactions for each, the total property value and the total value of commissions earned, using a 3\% share for both the buyer and seller sides of the transaction. Over 343,000 commission events are recorded in these nine counties in 2004. These records show 45,747 agents with at least one commission event in 477 unique zip codes for which census data reports a median home value.

Of the 107, 485 real estate agents and brokers with active licenses in 2004 in these nine counties, a majority did not have a commission event that year. The 46,846 individuals with at least one event represent $43.6 \%$ of the licensed group. Summary statistics for those with at least one event are shown in Table 1. Figure 1 shows a histogram of the number of events per agent. Overall, $19.91 \%$ of this group had only one commission event and $33.15 \%$ had two or fewer events.

Details of the housing market can be examined when commission events are combined with census data and viewed by zip code. There is a strong linear relationship between the number of housing units and population, with an average of 15 additional houses per 100 added populations. As expected, the number of commission events increases as the number of houses increases, with 16 more commission events per year per 1000 additional houses in a given zip code.

There is no relationship between the average number of commission events per agent and the number of houses in the zip code. This is consistent with a simple efficiency hypothesis that entry of new agents is likely when profit potential exists in the market.

Given the traditional $6 \%$ commission rate (split between buyer and seller agents) the earnings of an agent per transaction in a high-priced home market are higher than for a lowpriced market. This suggests that completing one or two transactions per year would be more attractive to potential entrants into this labor market in high-priced counties than in low-price areas. This may include individuals who are willing to work in real-estate sales part-time or who stand to save a considerable amount on commission costs when attempting to sell their own residence or when assisting family members or personal friends on an occasional basis. 
Am. J. of Economics and Business Administration 3 (4): 589-595, 2011

Table 2:Percentage of agents with 1 or 1-2 sales Vs. median home value, by county

\begin{tabular}{llll}
\hline & $\begin{array}{l}\text { Median } \\
\text { value }\end{array}$ & $\begin{array}{l}1 \text { sale } \\
(\%)\end{array}$ & $\begin{array}{l}\text { 1 or 2 sale } \\
(\%)\end{array}$ \\
\hline Alameda County & 303,100 & 23.01 & 36.54 \\
Orange County & 270,000 & 22.44 & 36.98 \\
Riverside County & 146,500 & 18.17 & 30.10 \\
Sacramento County & 144,200 & 18.54 & 31.54 \\
San Bernardino County & 131,500 & 17.75 & 30.37 \\
San Diego County & 227,200 & 18.19 & 31.05 \\
San Joaquin County & 142,400 & 15.96 & 26.43 \\
Santa Clara County & 446,400 & 22.96 & 38.48 \\
Stanislaus County & 125,300 & 14.52 & 23.51 \\
\hline
\end{tabular}

Table 3: Part-time percentage Vs. median home value, by county

\begin{tabular}{lll}
\hline & $\begin{array}{l}\text { Percentage } \\
\text { with 1 transaction }\end{array}$ & $\begin{array}{l}\text { Percentage } \\
\text { with 1 or 2 transactions }\end{array}$ \\
\hline Intercept & 0.1390 & 0.2341 \\
Slope coefficient & 2.3974 E-07 & 2.8383 E-07 \\
T & 4.1910 & 4.1120 \\
P-value & 0.0041 & 0.0045 \\
R-squared & 0.7150 & 0.7070 \\
$\mathrm{~N}$ & 9.0000 & 9.0000 \\
\hline
\end{tabular}

Table 4: Part-time percentage Vs. median home value, by zip code

\begin{tabular}{lll}
\hline & $\begin{array}{l}\text { Percentage } \\
\text { with 1 transaction }\end{array}$ & $\begin{array}{l}\text { Percentage } \\
\text { with 1 or 2 transactions }\end{array}$ \\
\hline Intercept & 0.1884 & 0.3099 \\
Slope coefficient & $8.32032 \mathrm{E}-08$ & $1.3767 \mathrm{E}-07$ \\
$\mathrm{~T}$ & 3.3100 & 4.10000 \\
P-value & 0.0010 & 0.00005 \\
R-squared & 0.1650 & 0.20300 \\
$\mathrm{~N}$ & 394.0000 & 394.00000 \\
\hline
\end{tabular}

The implication that part-time participation in this labor market is more attractive in highpriced areas can be tested with county or zip-code level data. The median home value is a highly significant factor in explaining the percentage of agents with a single commission event or with only one or two events ( $p$ value $<0.005)$. The data by county is in Table 2 and regression results are summarized in Table 3.

When evaluating this hypothesis using zip code level data, noise is introduced from many locations in which only a few homes were sold. To avoid this problem only zip codes are used in which 10 or more commission events occurred. The r-squared values fall but the median home price remains a significant factor. Results are in Table 4.

Entry: Number of agents per capita: Agents in a high-priced home market earn a larger commission per home sold than an agent in a low-price region. There is little reason to suggest that selling costs or selling effort should differ significantly between areas with different median home values. If the labor market for real estate professionals is efficient, meaning that information is available and entry is unconstrained, the potential for higher earnings in the high-price areas should attract additional real estate agents.
Table 5: Agents per capita Vs. median home value, all nine counties

\begin{tabular}{lllll}
\hline Slope coefficient & $\mathrm{T}$ & $\mathrm{P}$-value & $\mathrm{N}$ & $\mathrm{R}$-squared \\
\hline $0.172 \mathrm{E}-07$ & 4.263 & 0.00002 & 477 & 0.037
\end{tabular}

Table 6: Agents per capita Vs median home value by county-White heteroscedasticity-consistent estimates

\begin{tabular}{lllllc}
\hline County & Slope coefficient & $\mathrm{T}$ & $\mathrm{P}$-value & $\mathrm{N}$ & R-squared \\
\hline Alameda & $0.171 \mathrm{E}-07$ & 2.903 & $0.0058^{* *}$ & 45 & 0.202 \\
Orange & $0.079 \mathrm{E}-07$ & 2.082 & $0.0405^{*}$ & 83 & 0.012 \\
Riverside & $1.674 \mathrm{E}-07$ & 3.354 & $0.0014^{* *}$ & 65 & 0.649 \\
Sacramento & $0.330 \mathrm{E}-07$ & 1.449 & 0.1544 & 46 & 0.165 \\
San Bernardino & $0.127 \mathrm{E}-07$ & 2.427 & $0.0184^{*}$ & 59 & 0.059 \\
San Diego & $0.228 \mathrm{E}-07$ & 4.234 & $0.0001^{* *}$ & 87 & 0.101 \\
San Joaquin & $0.149 \mathrm{E}-07$ & 1.186 & 0.2488 & 23 & 0.053 \\
Santa Clara & $0.137 \mathrm{E}-07$ & 3.408 & $0.0013^{* *}$ & 52 & 0.401 \\
Stanislaus & $0.074 \mathrm{E}-07$ & 0.428 & 0.6748 & 17 & 0.004 \\
\hline
\end{tabular}

*: Significant at the $10 \%$ level; **: Significant at the $5 \%$ level

A good entry measure is the number of agents per capita. The above reasoning suggests that there should be a greater number of agents per capita in high-price regions than in low-price areas. Using data for all 477 zip codes, there is a positive and significant relationship between the number of agents per capita with at least one commission event and the median home price. The slope coefficient shows that there is an average increase of 0.172 agents per 1000 population for each $\$ 10,000$ increase in median home price.

When examined by county, the slope coefficients in separate regressions of agents per capita vs. median home value show positive coefficients in each of the nine counties and six of the nine coefficients are significant at the $10 \%$ level. Results are shown in Table 5 and 6.

Some outliers are present in zip codes with low populations and few home sales, but a large agent per capita ratio. Including these observations reduces the value of r-squared, but the OLS estimate is robust to changes in which outliers are removed.

Some heteroscedasticity is evident in several of the county regressions, but the OLS estimates are unbiased and corrections using White's heteroscedasticityconsistent estimator do not materially change the significance levels.

Number of commission events per agent: Economic efficiency in the real estate labor market also suggests that the annual earnings of agents in high-price and low price regions should be similar. If not, agents could migrate from low earnings areas to higher earnings areas. Since it has already been demonstrated that the number of agents per capita is larger in higher valued housing markets, it follows that there should be fewer commission events per agent in the high-priced markets. This hypothesis is supported by the data, with 0.49 fewer average transactions per agent for each $\$ 100,000$ increase in median price, as shown in Fig. 2 and Table 7. 
Am. J. of Economics and Business Administration 3 (4): 589-595, 2011

Table 7: Average number of commission events Vs. median home value (by zip code with at least 10 events)

\begin{tabular}{lllll}
\hline Slope coefficient & T & P-value & N & R-squared \\
\hline-4.903 E-06 & -6.835 & 0.00000 & 395 & 0.106
\end{tabular}

Table 8: Average agent earnings Vs median home value (by zip code with at least 10 events)

\begin{tabular}{lllll}
\hline Slope coefficient & $\mathrm{T}$ & $\mathrm{P}$-value & $\mathrm{N}$ & $\mathrm{R}$-squared \\
\hline 0.12902 & 13.678 & 0.00000 & 395 & 0.323 \\
\hline
\end{tabular}

The dollar value of commission earnings: Introducing risk into the model allows other factors to be considered. For example, an extensive literature has examined risk premiums in financial and labor markets and the risk Vs. return tradeoff. This tradeoff is also testable in the real estate labor market. Since there are fewer transactions per agent per year, on average, in high-price markets, each home sale in a high-price region comprises a larger percentage of an agent's annual income than in a low-priced region. Since most individuals are risk averse, an implication in this market is that high home price regions should have higher average earnings to compensate agents in those regions for the increased income risk per home sold.

This hypothesis is strongly supported by the data, as reported in Table 8 and depicted in Fig. 3. This result suggests that an earnings premium does exist to compensate agents in higher-priced markets for the risk associated with the lower number of average sales per year. All else equal, annual earnings per agent are higher by $\$ 129$ for each $\$ 1,000$ increase in the median home value.

Many other factors could help explain this result, however. The cost of living will be higher in a region with higher home prices, so the greater earnings could be a compensating differential for these higher living costs. Separate price indexes are not reported by zip code, so adjusting for this factor is not an easy task. It is reasonable to assume that living costs would not vary dramatically across neighboring zip codes in the same state except for the housing cost component.

The higher earnings in higher priced markets may also partially reflect a quality differential if more experienced, more educated, or better performing agents sell in high-priced areas. This could be compared to the stratification of waiters by quality of restaurant, or labor markets in car sales or insurance where income is at least partially determined by a percentage commission or tip.

Additional model specifications: The regression results change slightly with a more robust specification. Consider the following model.

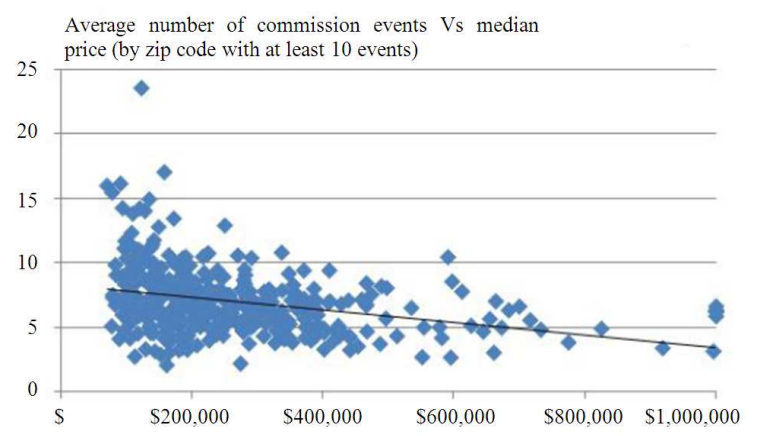

Fig. 2: Average number of commission events Vs median home value

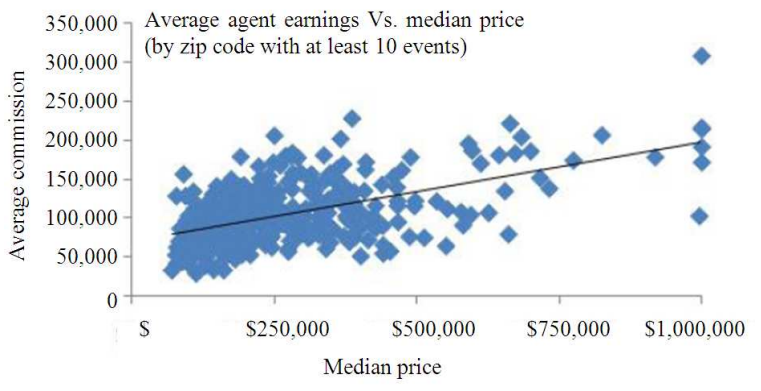

Fig. 3: Average agent earnings Vs median home value

Dependent variable: Average number of commission events per agent.

Independent variables:

\# Houses $=$ The number of houses in the zip code Median value $=$ Median home value in the zip code Population $=$ Population in the zip code

When examined separately, the simple regression of commission events Vs the number of houses showed no relationship. The expectation that the average number of commission events should fall as the median home value increases has already been discussed. Although population is correlated with the number of houses in a given zip code, population increases (all else equal) would be expected to have no impact on the average number of events per agent. If the market is efficient and entry is not blocked, the number of agents would increase instead. The results in Table 9 confirm the inverse relationship for median value, but the number of houses and population show significant effects, with opposite signs.

These results show 0.595 fewer average annual transactions per agent for each $\$ 100,000$ increase in median price, which is consistent with the findings in Table 7. The negative. 
Table 9: Dependent variable $=$ Average number of commission events per agent (by zip code with at least 10 events, $\mathrm{n}=395$ )

\begin{tabular}{|c|c|c|c|c|}
\hline Variable & Slope & $\mathrm{T}$ & P-value & VIF \\
\hline \# houses & -6.093 E-05 & 4.340 & 0.00002 & 2.99 \\
\hline Median value & -5.947 E-06 & -8.307 & 0.00000 & 1.07 \\
\hline Population & -6.093 E-05 & -5.631 & 0.00000 & 3.08 \\
\hline
\end{tabular}

Adj. R-squared $=0.167$

Table 10: Dependent variable $=$ Average of total commissions (in dollars, for agents with at least one commission event) (by zip code with Sat least 10 events, $\mathrm{n}=395$ )

\begin{tabular}{llrrr}
\hline Variable & Slope & \multicolumn{1}{c}{ T } & P-value & VIF \\
\hline \# houses & 2.5459 & 3.160 & 0.00170 & 2.99 \\
Median value & 0.1220 & 12.621 & 0.00000 & 1.07 \\
Population & -0.4239 & -2.903 & 0.00391 & 3.08 \\
\hline Adj.
\end{tabular}

Adj. R-squared $=0.335$

Table 11: Dependent variable $=$ Average of total commissions (in dollars, for agents with at least one commission event) (by zip code with at least 10 events, $n=395$ )

\begin{tabular}{lrrl}
\hline Variable & Slope & \multicolumn{1}{c}{ T } & P-value \\
\hline Median value & 0.1150 & 11.913 & 0.00000 \\
\# houses per capita & 121269.9000 & 4.712 & 0.00000 \\
\hline
\end{tabular}

Adj. R-squared $=0.356$

Population coefficient may reflect the lumpy nature of entry. The value indicates that the average number of commission events per agent will fall by 0.609 for each 10,000 increase in population. Lower population regions will have fewer home sales, which will support fewer real estate professionals. A small number of agents would need to share limited commissions with other agents. Entry of an additional agent in a small market could dilute the average number of sales per agent too much to make entry profitable. As the population grows the larger region will support additional agents, so the average number of transactions per agent will fall.

Table 10 shows the results when the dependent variable is average agent earnings. The risk premium hypothesis is still supported. Although the number of commission events falls, theaverage total commission rises as the median house value rises. Specifically, average annual earnings increase by $\$ 122$ per $\$ 1000$ increase in median home value, which is consistent with the result in Table 8 .

The positive coefficient for the number of houses may simply be capturing an income effect. With a given population (and assuming family size is constant), an increase in the number of houses can be viewed an increase in the percentage of homeowners vs. renters. The number of houses per capita can thus be considered a proxy for income if higher income is associated with home ownership. Using the ratio of houses to population instead of the two variables separately also reduces any multicollinearity concerns. If the average earnings of agents is correlated with the average income in the region in which they work, then the average earnings per agent should be positively associated with the number of houses per capita.

The results shown in Table 11 support this hypothesis. After accounting for affects due to variation in the median home value, agents in higher income regions (as measured by the proxy of houses per capita) earn an average of $\$ 1,213$ more per year for each $1 \%$ increase in the number of houses per capita.

\section{CONCLUSION}

Using data from 2004 for over 200,000 transactions handled by nearly 47,000 real estate professionals in nine California counties and applying two assumptions-that the commission rate on home sales is constant and that entry into the real estate labor market is easy-several hypotheses about market efficiency are supported. Significant findings are that areas with higher median home prices have a greater number of part-time real estate agents and an increased number of agents per capita. There are fewer average commission events per agent in areas with higher housing prices, but a higher level of total commission earnings per agent to compensate for the added income risk per completed transaction.

\section{REFERENCES}

Clayton, J., 1998. Further evidence on real estate market efficiency. J. Real Estate Res., 15: 41-57.

Crockett J.H., 1982. Competition and efficiency in transacting: The case of residential Real Estate Brokerage. Real Estate Econ., 10: 209-227. DOI: 10.1111/1540-6229.00264

Goolsby, W.C. and B.J. Childs, 1988. Brokerage firm competition in real estate commission rates. J. Real Estate Soc., 3: 79-85.

Hsieh, C.T. and E. Moretti, 2003. Can free entry be inefficient? Fixed commissions and social waste in the real estate industry. J. Political Econ., 111: 1076-1122. DOI: $10.1086 / 376953$

Johnson, L.L. and C. Loucks, 1986. The effect of state licensing regulations on the real estate brokerage industry. Real Estate Econ., 14: 567-582. DOI: 10.1111/1540-6229.00404

Jud, G.D. and D.T. Winkler, 2000. A note on licensing and the market for real estate agents. J. Real Estate Financ. Econ., 21: 175-184. DOI: 10.1023/A:1007844010486

Levitt, S.D. and C. Syverson, 2008. Market distortions when agents are better informed: The Value of information in real estate transactions. Rev. Econ. Stat., 90: 599-611. DOI: 10.1162/rest.90.4.599 
Miceli, T.J., 1992. The Welfare effects of non-price competition among real estate brokers. Real Estate Econ., 20: 519-532. DOI: 10.1111/15406229.00594
Turnbull, G.K., 1996. Real estate brokers, nonprice competition and the housing market. Real Estate Econ., 24: 293-316. DOI: 10.1111/15406229.00692 